\title{
Flight Testing Small, Electric Powered Unmanned Aerial Vehicles
}

Jon N. Ostler

Brigham Young University - Provo

Follow this and additional works at: https://scholarsarchive.byu.edu/etd

Part of the Mechanical Engineering Commons

\section{BYU ScholarsArchive Citation}

Ostler, Jon N., "Flight Testing Small, Electric Powered Unmanned Aerial Vehicles" (2006). Theses and Dissertations. 387.

https://scholarsarchive.byu.edu/etd/387

This Thesis is brought to you for free and open access by BYU ScholarsArchive. It has been accepted for inclusion in Theses and Dissertations by an authorized administrator of BYU ScholarsArchive. For more information, please contact scholarsarchive@byu.edu, ellen_amatangelo@byu.edu. 


\section{FLIGHT TESTING SMALL, ELECTRIC POWERED UNMANNED AERIAL VEHICLES}

by

Jon Neal Ostler

A thesis submitted to the faculty of

Brigham Young University

in partial fulfillment of the requirements for the degree of

Master of Science

Department of Mechanical Engineering

Brigham Young University

April 2006 


\title{
BRIGHAM YOUNG UNIVERSITY
}

\section{GRADUATE COMMITTEE APPROVAL}

\author{
of a thesis submitted by
}

Jon Neal Ostler

This thesis has been read by each member of the following graduate committee and by majority vote has been found to be satisfactory.

Date

Date

Date
W. Jerry Bowman, Chair

Timothy W. McLain

Deryl O. Snyder 


\title{
BRIGHAM YOUNG UNIVERSITY
}

As chair of the candidate's graduate committee, I have read the thesis of Jon Neal Ostler in its final form and have found that (1) its format, citations, and bibliographical style are consistent and acceptable and fulfill university and department style requirements; (2) its illustrative materials including figures, tables, and charts are in place; and (3) the final manuscript is satisfactory to the graduate committee and is ready for submission to the university library.

Date

Accepted for the Department
W. Jerry Bowman

Chair, Graduate Committee
Matthew R. Jones

Graduate Coordinator

Accepted for the College

\author{
Alan R. Parkinson \\ Dean, Ira A. Fulton College of \\ Engineering and Technology
}




\author{
ABSTRACT \\ FLIGHT TESTING SMALL, ELECTRIC POWERED \\ UNMANNED AERIAL VEHICLES \\ Jon Neal Ostler \\ Department of Mechanical Engineering \\ Master of Science
}

Flight testing methods are developed to find the drag polar for small UAVs powered by electric motors with fixed-pitch propellers. Wind tunnel testing was used to characterize the propeller-motor efficiency. The drag polar was constructed using data from flight tests. The proposed methods were implemented for a small UAV. A drag polar was found for this aircraft with $C_{D_{o}}$ equal to $0.021, K_{1}$ equal to 0.229 , and $K_{2}$ equal to -0.056 . This drag polar was then used to find the following performance parameters; maximum velocity, minimum velocity, velocity for maximum range, velocity for maximum endurance, maximum rate of climb, maximum climb angle, minimum turn radius, maximum turn rate, and maximum bank angle. Applications in UAV control and mission planning are also proposed. 


\section{ACKNOWLEDGMENTS}

I would like to acknowledge all of those who have assisted me with this thesis. Foremost is Dr. Bowman. He has taught me as much about life as he has about aircraft aerodynamics and performance. It can truly be said that without him this work would not have been possible. I would also like to thank Dr. McLain, Dr. Snyder, and Dr. Beard. They have always been encouraging and supportive. I would like my friends and associates in BYU's MAGICC Lab to know that I appreciate all of the time and knowledge they have contributed. My wife, Shawna, has been my best friend through this process. She has put many of her own interests on hold in order to support me. I am very grateful for her. Finally, I want to thank my Heavenly Father. All that I have has been mercifully granted by him. 


\section{Contents}

$\begin{array}{lll}\text { Acknowledgments } & \text { v }\end{array}$

$\begin{array}{ll}\text { List of Tables } & \text { ix }\end{array}$

List of Figures $\quad$ xii

1 Introduction 1

1.1 Motivation ......................... 1

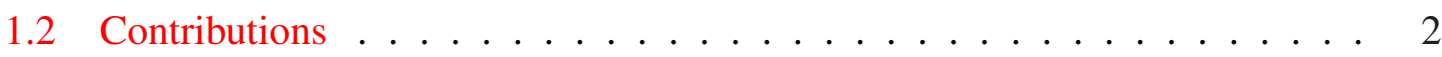

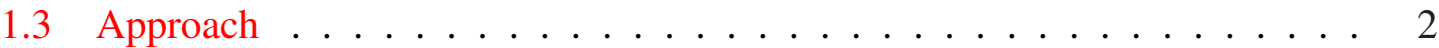

2 Finding the Drag Polar From Flight Tests 3

2.1 Introduction . . . . . . . . . . . . . . . . . . 3

2.2 Theory............................... 4

2.3 Ground Test Methods . . . . . . . . . . . . . . . . . . . . 6

2.4 Flight Test Method . . . . . . . . . . . . . . . . . . . 7

2.5 Alternative Methods . . . . . . . . . . . . . . . . . . 7

3 Finding Performance Parameters from the Drag Polar 9

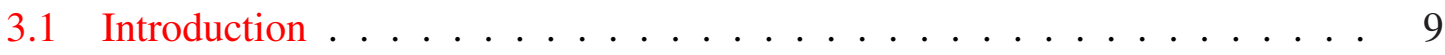

3.2 Power Required and Maximum Velocity . . . . . . . . . . . . . . . . . . 9

3.3 Rate of Climb . . . . . . . . . . . . . . . . . . . 11

3.4 Range and Endurance . . . . . . . . . . . . . . . . . . . . 12

3.5 Turn Performance . . . . . . . . . . . . . . . . . . . . 13 
$\begin{array}{lll}4 & \text { Results } & 17\end{array}$

4.1 Introduction . . . . . . . . . . . . . . . . . . 17

4.2 Hardware . . . . . . . . . . . . . . . . . . 17

4.3 Data Acquisition . . . . . . . . . . . . . . . . . 18

4.4 Propeller-Motor Efficiency . . . . . . . . . . . . . . . . 20

4.5 Drag Polar . . . . . . . . . . . . . . . . . 21

4.6 Power Required and Maximum Velocity . . . . . . . . . . . . . . . 25

4.7 Minimum Velocity . . . . . . . . . . . . . . . . . . . 25

4.8 Rate of Climb . . . . . . . . . . . . . . . . . 26

4.9 Range and Endurance . . . . . . . . . . . . . . . . . . . 26

4.10 Turn Performance . . . . . . . . . . . . . . . . . . . . . 27

5 Applications $\quad 29$

5.1 Introduction . . . . . . . . . . . . . . . . . . . . . . 29

5.2 Throttle Control . . . . . . . . . . . . . . . . . . . . . 29

5.3 Climb Control . . . . . . . . . . . . . . . . . . . . . . 31

5.4 Mission Planning . . . . . . . . . . . . . . . . . . . . 31

5.5 Unpowered Flight . . . . . . . . . . . . . . . . . . . . . 32

5.6 Model Validation . . . . . . . . . . . . . . . . . . . . . 32

6 Conclusions and Recommendations 35

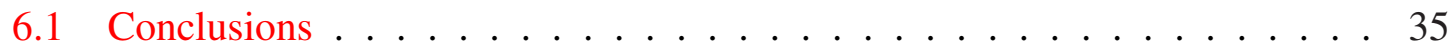

6.2 Future Work . . . . . . . . . . . . . . . . . . 36

$\begin{array}{ll}\text { Bibliography } & 37\end{array}$ 


\section{List of Tables}

4.1 Bias error for measurements made during wind tunnel testing and . . . . . 24 


\section{List of Figures}

2.1 Example plot of $C_{D}$ vs $C_{L}^{2}$. Reference Kimberlin[1]. . . . . . . . . 5

2.2 Example motor-propeller efficiency surface. . . . . . . . . . . . . . . 6

3.1 Example power available and power required curves. . . . . . . . . . . . 10

3.2 Example rate of climb plot. . . . . . . . . . . . . . . . . 11

3.3 Climbing velocities. . . . . . . . . . . . . . . . 12

3.4 Velocity for maximum range and maximum endurance. . . . . . . . . . . . 12

3.5 Maximum load factor verses velocity for the two limiting conditions. . . . . 15

3.6 Minimum turn radius(left) and maximum turn rate(right). . . . . . . . . . . 16

4.1 Unicorn small UAV used in flight tests. . . . . . . . . . . . . . . . . . . . 18

4.2 Kestral 2.0 autopilot, photo used with permission, . . . . . . . . . . . . . 19

4.3 Dwyer 1/8 inch diameter pitotstatic tube and Digikey G-P4V mini 5 inch

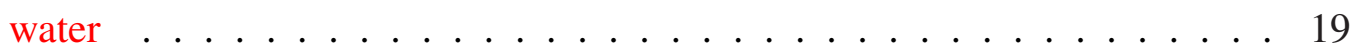

4.4 Propeller-motor efficiency surface of a MEGA . . . . . . . . . . . . . 20

4.5 Efficiency surface showing average run efficiency. . . . . . . . . . . . . 21

4.6 Drag polar of the Unicorn UAV. Error represents a 95\% confidence interval. 22

4.7 Drag polar superimposed on flight test results. . . . . . . . . . . . . . 23

$4.8 C_{D}$ vs $C_{L}^{2}$ for the Unicorn UAV(left). Simplified drag polar . . . . . . . . . 23

4.9 Power available and power required for the Unicorn UAV powered . . . . . 25

4.10 Rate of climb verses velocity(left). Maximum climb . . . . . . . . . . . 26

4.11 Velocity for maximum range and maximum endurance. . . . . . . . . . . 27

4.12 Turn performance parameters for the Unicorn UAV. . . . . . . . . . . . 28

5.1 PID airspeed controller. . . . . . . . . . . . . . . . . . . . . 29

5.2 PID airspeed controller with feedforward. . . . . . . . . . . . . 30

5.3 Airspeed error before feedforward(left) and after feedforward(right). . . . . 30 
5.4 Predicted drag polars verses flight test results. . . . . . . . . . . . . 33 


\section{Chapter 1}

\section{Introduction}

\subsection{Motivation}

Small, electric powered, unmanned aerial vehicles (UAVs) are a subclass of UAVs that do not lend themselves to flight testing methods developed for larger aircraft that are powered by gas turbine or internal combustion engines. Examples of small electric planes are Lockheed Martin's Desert Hawk and AeroVironment's Dragon Eye. Traditional flight testing methods are not acceptable for small UAVs for the following reasons. First, in-flight engine power cannot be determined by measuring fuel flow, as it is done for engines that burn fuel. Second, electric powered UAVs do not decrease in weight over time. Finally data acquisition systems in small UAVs are limited in size and weight.

Flight test methods for large manned airplanes powered by gas turbine and internal combustion engines have been well established for many years. An abundance of literature exists that describes flight test methods for large aircraft. Recent research has begun to build the body of knowledge on many aspects of flight testing small UAVs. There is available literature that discusses flight testing small UAVs to quantify stability and dynamics [2],[3]. Flight testing has also been done to observe the usefulness of the latest developments. For example a new control law [4] or a novel wing structure [5]. Some writing has been published that discusses flight testing scale models for the purpose of discerning characteristics of full-size aircraft [6],[7]. However, there appears to be a shortage of published material that addresses performance flight testing for small electric UAVs.

Williams and Harris [8] briefly address the perceived difficulties in performance flight testing of small UAVs. Hiller [9] finds a drag polar using decent methods, but does 
so to determine the effect of flaps on drag and does not discuss performance. Abdulrahim [10] finds the glide slope and rate of climb for a biologically inspired UAV, but does not look at other performance parameters or find the drag polar. It seems that little is available that details how the drag polar and performance of a small electric UAV can be determined from flight testing.

\subsection{Contributions}

This work has developed flight test methods for small unmanned aerial vehicles powered by electric motors with fixed pitch-propellers. A reliable technique for finding the drag polar has been developed. In addition this thesis describes equations and graphical methods needed to calculate maximum velocity, range, endurance, rate of climb, climb angle, and turn performance. Recommendations are also made as to how these performance parameter can be used to improve the control and operation of small electric UAVs.

\subsection{Approach}

When quantifying the performance of an aircraft, the most important object that can be found from flight tests is the drag polar. Kimberlin [1] says it this way, "If the drag polar of an aircraft is accurately determined and the thrust, or thrust horsepower, available is known then all of the performance characteristics of the subject airplane may be calculated." The approach taken here was to first determine the drag polar from flight tests and then calculate other performance parameters from this drag polar. When possible, the parameters found from calculations are validated with further flight tests. 


\section{Chapter 2}

\section{Finding the Drag Polar From Flight Tests}

\subsection{Introduction}

The drag polar is a powerful equation that relates the coefficient of lift to the coefficient of drag for a given aircraft. The plot of this equation is also termed the drag polar. The drag polar is useful in characterizing an aircraft because it is dependent on distinguishing features including the weight of the aircraft, the airfoil used, protuberances, and the shape of the fuselage. Also, very important is the fact that the drag polar can be used to calculate other performance parameters.

Equation (2.1) is one form of the drag polar

$$
C_{D}=C_{D_{o}}+K_{2} C_{L}+K_{1} C_{L}^{2}
$$

where $C_{D}$ is the coefficient of drag, $C_{L}$ is the the coefficient of lift, $C_{D_{o}}$ is the minimum drag coefficient, and $K_{2}$ and $K_{1}$ are constants. If the assumption is made that minimum drag occurs at zero lift the drag polar can be expressed as

$$
C_{D}=C_{D_{o}}+K C_{L}^{2}
$$

While this assumption is valid for many aircraft, steps should be taken to verify its usability for the aircraft being flight tested.

The remaining sections in this chapter describe how the drag polar can be found for a small electric power UAV. The theory section derives the necessary equations. The next 
two sections, Ground Test Methods and Flight Test Method describe actual tests needed to calculate the drag polar.

\subsection{Theory}

In order to measure the drag polar for a small $\mathrm{UAV}, C_{D}$ and $C_{L}$ must be reduced to measurable parameters. Once $C_{D}$ and $C_{L}$ have been found for various flight conditions, graphical methods can be used to find the remaining constants present in Eq. (2.1) or Eq. (2.2). Assuming steady level flight, the equations of flight are

$$
W=L=\frac{1}{2} \rho V^{2} C_{L} S
$$

and

$$
T_{r}=D=\frac{1}{2} \rho V^{2} C_{D} S
$$

The weight of the aircraft $(W)$ is equal to the lift $(L)$ and the thrust or thrust required $\left(T_{r}\right)$ is equal to the drag $(D) . \rho$ is the density of air, $V$ is the free stream velocity, and $S$ is the wing area.

The power required $\left(P_{r}\right)$ can be found by multiplying both sides of Eq. (2.4) by velocity, which then becomes Eq. (2.5). If the efficiency $(\eta)$ of the propeller-electric motor combination is known, then Eq. (2.6) can be used to describe the relationship between the mechanical power required for flight and the electrical power $\left(P_{e}\right)$ supplied to the motor. Electrical power can also be formed from the product of the voltage $(E)$ and the current $(i)$ into the electric motor, Eq. (2.7).

$$
\begin{gathered}
P_{r}=T_{r} V=\frac{1}{2} \rho V^{3} C_{D} S \\
P_{r}=\eta P_{e} \\
P_{e}=i E
\end{gathered}
$$


Combining Eq. (2.5), (2.6), and (2.7) and solving for $C_{D}$ gives Eq. (2.8). Solving Eq. (2.3) for $C_{L}$ gives Eq. (2.9).

$$
\begin{aligned}
& C_{D}=\frac{2 i E \eta}{\rho V^{3} S} \\
& C_{L}=\frac{2 W}{\rho V^{2} S}
\end{aligned}
$$

All of the variables in Eq. (2.8) and (2.9) can be measured for a given airplane in a given flight condition. The only remaining parameters in the drag polar that are not known are $C_{D_{o}}$ and either $K_{2}$ and $K_{1}$, or $K$. These can be found graphically by plotting $C_{D}$ verses $C_{L}$ and then fitting it with a second order polynomial in order to find the constants $C_{D_{o}}$, $K_{2}$ and $K_{1}$. In the case of the simplified drag polar if $C_{D}$ is plotted verses $C_{L}^{2}$ as shown in Fig. (2.1)[1], the slope of this plot is equal to $K$ and the y-intercept is equal to $C_{D_{o}}$.

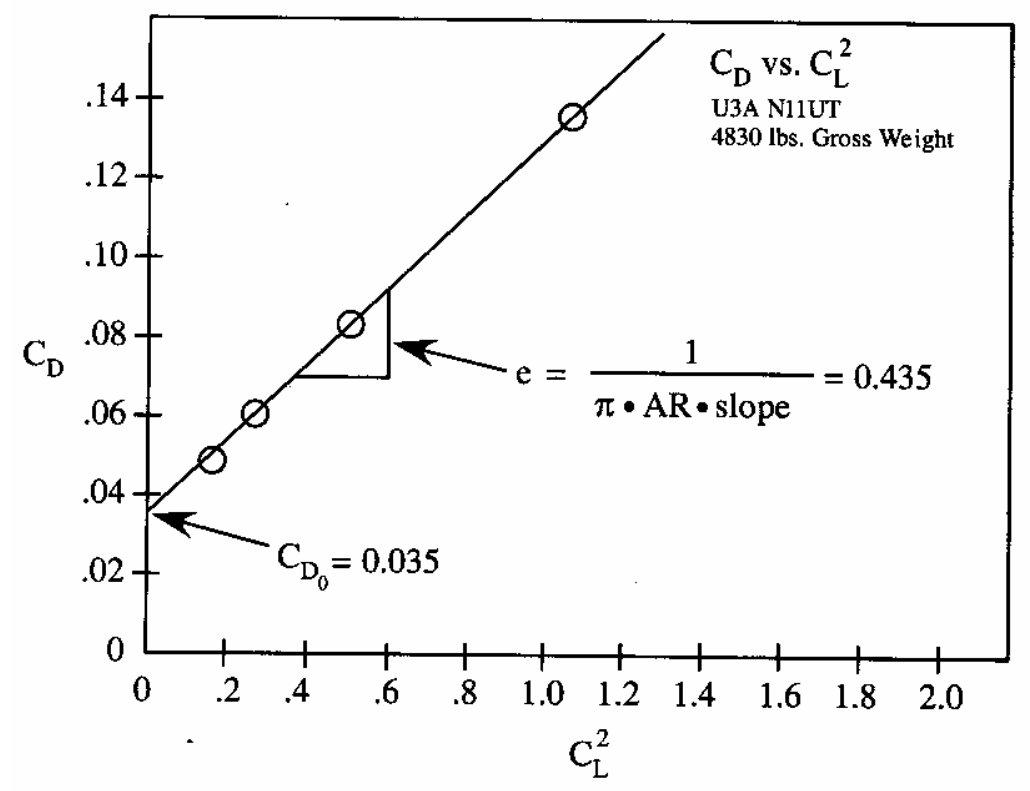

Figure 2.1: Example plot of $C_{D}$ vs $C_{L}^{2}$. Reference Kimberlin[1]. 


\subsection{Ground Test Methods}

Before flight tests can be performed for an aircraft, the efficiency of the motorpropeller combination must be found. During flight testing, data will be taken at many different throttle positions. Because of this, efficiency must be determined over the range of possible power settings and vehicle velocities.

The motor-propeller efficiency can be found from wind tunnel testing. The thrust produced by the motor-propeller combination is measured at various throttle and wind tunnel airspeed settings that include the estimated flight envelope of the aircraft to be tested. At each test point, current and voltage into the motor are measured as well as airspeed and the thrust produced. Efficiency is calculated using Eq. (2.10), dividing the mechanical power out of the motor, $P_{\text {out }}$, by the electrical power into the motor.

$$
\eta=\frac{T V}{i E}=\frac{P_{o u t}}{P_{e}}
$$

Then, by plotting $P_{e}, V$, and $\eta$, a surface plot of efficiency can be obtained. Fig. (2.2) is an example of this plot.

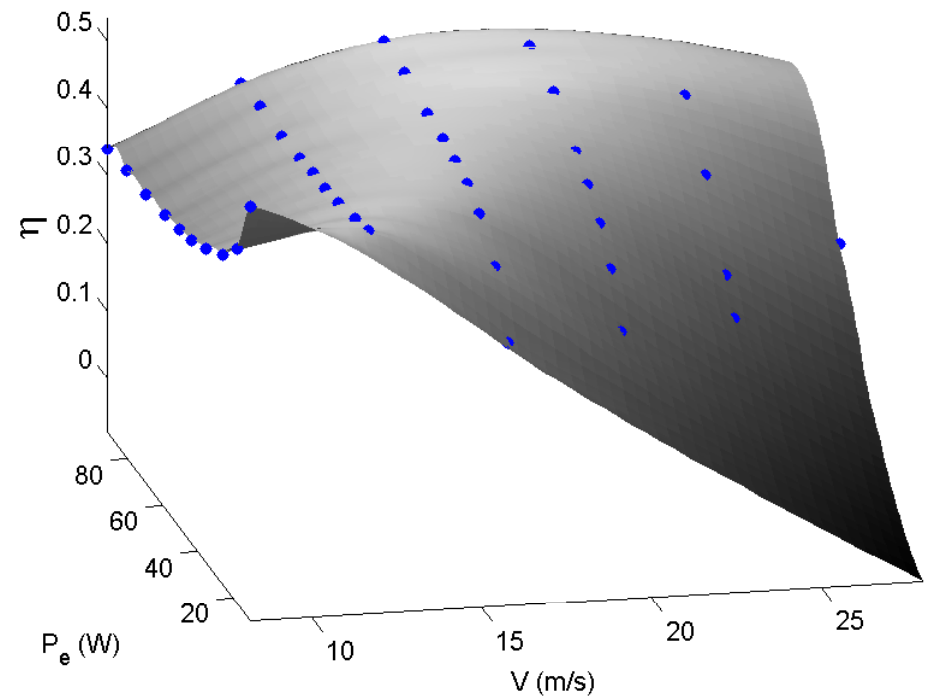

Figure 2.2: Example motor-propeller efficiency surface. 
The thrust and power at the maximum throttle setting should be recorded for each airspeed. These values are plotted against velocity in order to construct the thrust available and power available curves. These plots will be used latter in the calculation of other performance parameters.

Before flight testing, the aircraft's total weight and wing area need to be measured. The density of the ambient air also needs to be determined. This can be estimated by measuring air temperature and barometric pressure and then calculating air density using the ideal gas law.

\subsection{Flight Test Method}

After ground testing has been performed, the only parameters still needed to calculate $C_{L}$ and $C_{D}$ are $V, i$, and $E$. If these parameters can be measured while the test aircraft is at a constant velocity in steady level flight then $C_{L}$ and $C_{D}$ can be calculated using Eq. (2.8) and Eq. (2.9) and then plotted against each other. This wil create one point of the drag polar. If this is repeated for multiple velocities, then an approximation of the drag polar can be created. Therefore, an appropriate flight test is to fly the UAV in a straight and level path at a constant throttle setting over a large distance. During this constant throttle run, multiple data points should be taken in which the airspeed, current, and voltage to the motor are measured. These data points can then be averaged and used to estimate precision error. Multiple runs should be performed at a range of throttle settings.

\subsection{Alternative Methods}

The method just described has been successfully used to find the drag polar of a small electric powered UAV. The results will be presented later in this thesis. Two alternative methods could also be used. First if the position of a small UAV can be accurately estimated, then the glide polar method described by Kimberlin may be used[1]. A third method is similar to what has already been presented but involves measuring the RPM of the propeller in flight. RPM sensors are available that are small enough to be mounted on a small UAV. If one of these sensors were integrated with the data acquisition system on the test aircraft then the following method could used. 
Starting with Eq. (2.3) and Eq. (2.4) given above and solving these for $C_{L}$ and $C_{D}$ respectively, yields Eq. (2.11) and Eq. (2.12).

$$
\begin{gathered}
C_{L}=\frac{2 W}{\rho V^{2} S} \\
C_{D}=\frac{2 T_{r}}{\rho V^{3} S}
\end{gathered}
$$

The $T_{r}$ term in Eq. (2.12) could be found from wind tunnel testing in a similar manner to that described for efficiency. The thrust produced by the motor-propeller combination and the RPM of the propeller would be measured at various throttle and airspeed settings in a wind tunnel. This would make it possible to plot RPM, velocity and thrust thus making a thrust surface similar to the efficiency surface. This surface would be used to determine the thrust produced by the propeller for specific RPM and airspeed measurements taken during flight tests.

This method does require adding more hardware to the data acquisition system. However, it has the potential to be more accurate. This is because it does not depend on a knowledge of motor efficiency which could change with use and shifting environmental conditions. 


\section{Chapter 3}

\section{Finding Performance Parameters from the Drag Polar}

\subsection{Introduction}

After the drag polar has been found for a particular aircraft it can be used to calculate important performance parameters including power required, rate of climb, range, endurance, minimum turn radius, maximum turn rate, minimum bank angle, and maximum velocity. The following sections present equations and graphical methods for finding these parameters. The methods presented in this chapter are based on the drag polar that does not assume minimum drag occurs at zero lift (see Eq. (2.1)).

\subsection{Power Required and Maximum Velocity}

The drag polar can be used to construct the power required curve. Solving Eq. (2.3) and Eq. (2.5) for $C_{L}$ and $C_{D}$ respectively, they become Eq. (3.1) and Eq. (3.2).

$$
\begin{gathered}
C_{L}=\frac{2 W}{\rho V^{2} S} \\
C_{D}=\frac{2 P_{r}}{\rho V^{3} S}
\end{gathered}
$$

If Eq. (3.1) and Eq. (3.2) are substituted into the drag polar equation the following relationship results.

$$
\frac{2 P_{r}}{\rho V^{3} S}=C_{D_{o}}+K_{2}\left(\frac{2 W}{\rho V^{2} S}\right)+K_{1}\left(\frac{2 W}{\rho V^{2} S}\right)^{2}
$$


Solving this equation for power required gives

$$
P_{r}=C_{D_{o}} \frac{1}{2} \rho V^{3} S+K_{2} W V+\frac{K_{1} W^{2}}{\frac{1}{2} \rho V S} .
$$

The only term in Eq. (3.4)that is not constant is velocity. The graph of Eq. (3.4) is the power required curve shown in Fig. (3.1).

As described earlier, in a previous section on ground testing, wind tunnel data can be used to create the power available curve. Fig. (3.1) shows an example of power required and power available plotted on the same graph.

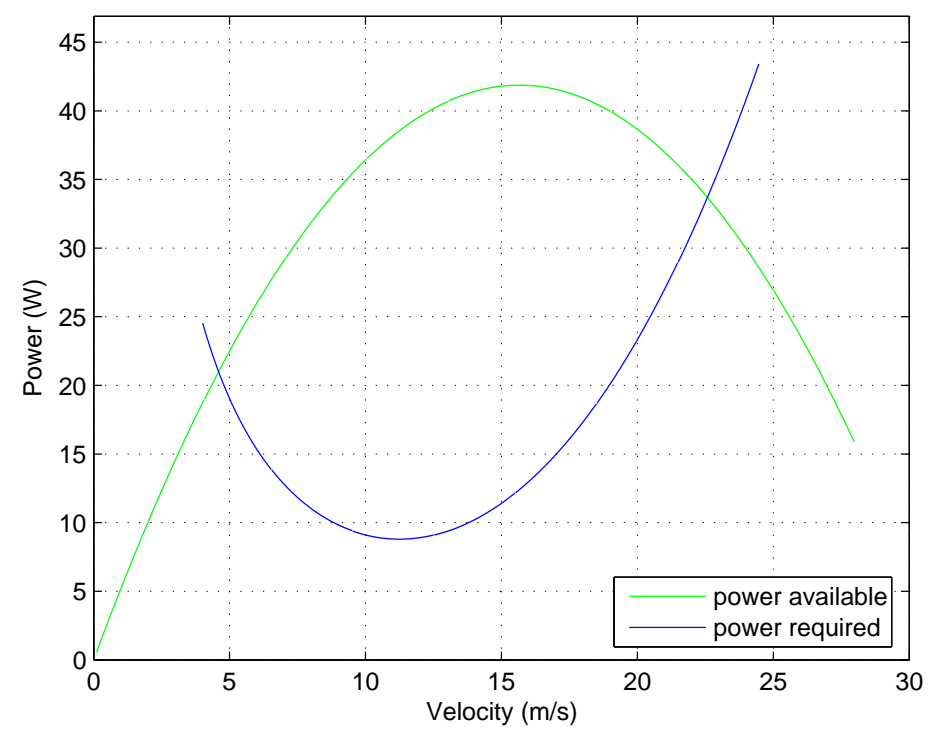

Figure 3.1: Example power available and power required curves.

This plot is useful when using graphical methods to find maximum velocity and rate of climb. On the right side of the plot, the point at which the power available curve crosses below the power required curve indicates maximum velocity. 


\subsection{Rate of Climb}

The difference between the power available curve and the power required curve represents the excess power or the power available for constant velocity climbing. Rate of climb is equal to excess power divided by the weight of the airplane[11] and is given by Eq. (3.5), where $R / C$ is the aircrafts rate of climb. A plot of rate of climb verses velocity can be seen in Fig. (3.2).

$$
R / C=\frac{P_{a}-P_{r}}{W}
$$

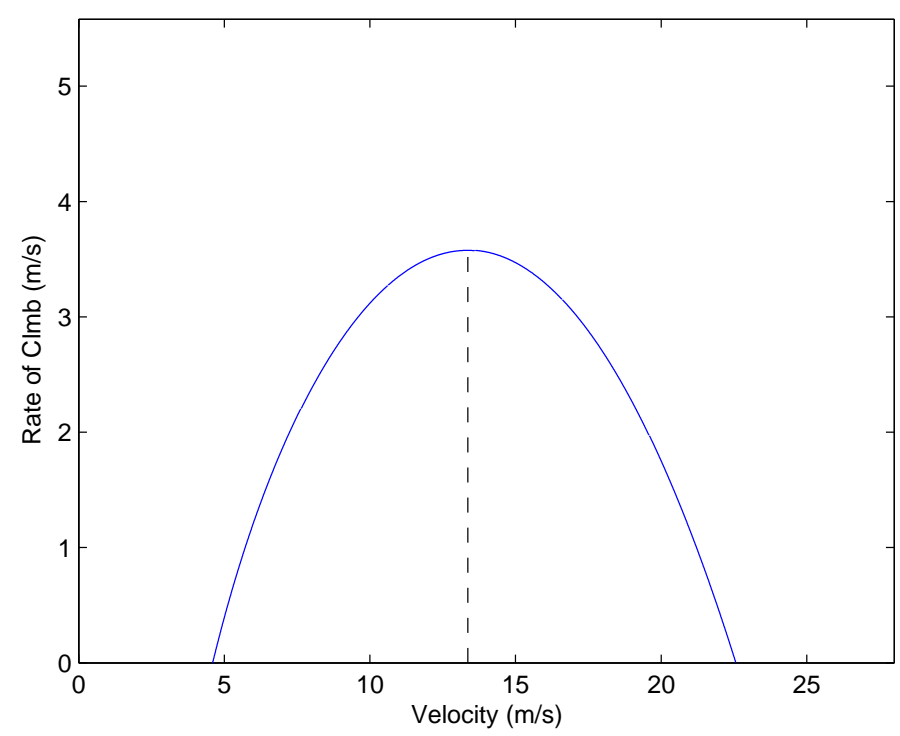

Figure 3.2: Example rate of climb plot.

The diagram in Fig. (3.3) illustrates the three different rates of change of position with respect to time for unaccelerated climbing. The climb angle $\gamma$ is given by Eq. (3.6), where $V$ is the airspeed of the aircraft. This equation can be used together with the rate of climb plot to create a plot of climb angle verses velocity. The maximum climb angle can then be determined from this plot. 


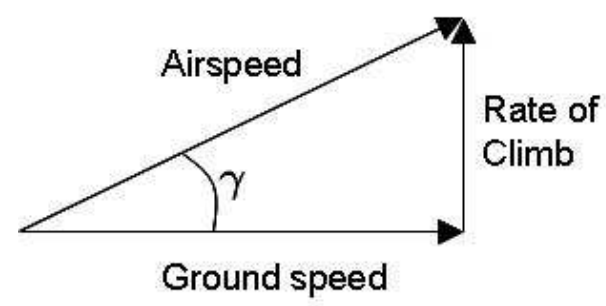

Figure 3.3: Climbing velocities.

$$
\gamma=\arcsin \left(\frac{R / C}{V}\right)
$$

\subsection{Range and Endurance}

The power required curve can further be used to find the velocity at which an airplane should fly in order to achieve maximum endurance. Endurance is maximized when power required is minimized. Therefore, the velocity at which power required is a minimum is also the velocity for maximum endurance. This is shown graphically in Fig. (3.4). Similarly, maximum range is achieved when the thrust required is a minimum. The velocity for minimum thrust required corresponds to maximum range and the maximum lift to drag ratio and. An example plot of thrust required is shown in Fig. (3.4).
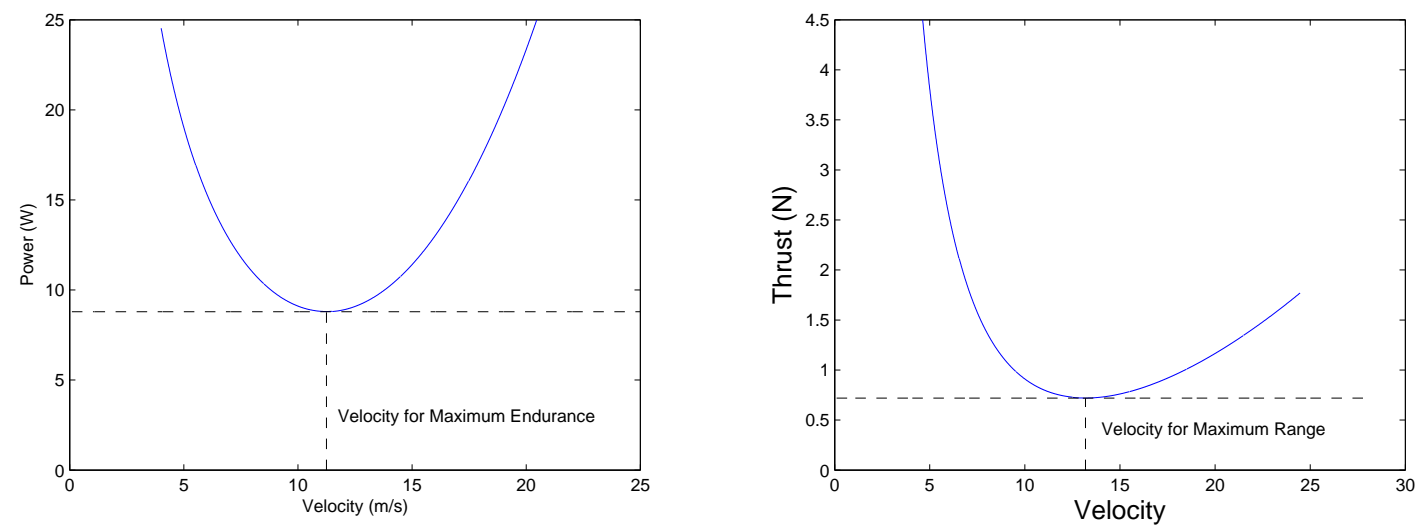

Figure 3.4: Velocity for maximum range and maximum endurance. 


\subsection{Turn Performance}

Minimum turn radius, maximum turn rate, and maximum bank angle will be discussed here for a UAV in a steady level turn. All of these parameters can be found using the drag polar generated from flight testing. Many of the following thoughts and derivations are patterned after Anderson[12]. The main difference being that the form of the drag polar used here makes no assumption that minimum drag occurs at zero lift.

Anderson provides the following equations for turn radius $R$, turn rate $\omega$, and bank angle $\phi$ assuming a constant velocity level turn.

$$
\begin{aligned}
& R=\frac{V^{2}}{g \sqrt{n^{2}-1}} \\
& \omega=\frac{g \sqrt{n^{2}-1}}{V^{2}} \\
& \phi=\arccos \frac{1}{n}
\end{aligned}
$$

where $g$ is the acceleration due to gravity and $n$ is the load factor defined as $L / W$. This definition of the load factor makes the above equations look deceptively simple. In order to minimize turn radius velocity needs to be minimized and the load factor maximized. Maximizing turn rate also requires velocity to be minimized and the load factor maximized. It is important to note however, that the load factor is constrained by both the maximum coefficient of lift, or stall, and the thrust available. A discussion on this dependence follows below.

Equations (3.10) and (3.11), which are the equations of flight for a steady level turn, can be used to derive a relationship between the load factor and thrust available.

$$
\begin{gathered}
L=n W=\frac{1}{2} \rho V^{2} C_{L} S \\
T=D=\frac{1}{2} \rho V^{2} C_{D} S .
\end{gathered}
$$

Solving for $C_{L}$ and $C_{D}$ gives

$$
C_{L}=\frac{2 n W}{\rho V^{2} S}
$$


and

$$
C_{D}=\frac{2 T}{\rho V^{2} S}
$$

Substituting $C_{L}$ and $C_{D}$ into the drag polar (Eq. (2.1)) yields the following equation.

$$
\frac{2 T}{\rho V^{2} S}=C_{D_{o}}+K_{2}\left(\frac{2 n W}{\rho V^{2} S}\right)+K_{1}\left(\frac{2 n W}{\rho V^{2} S}\right)^{2}
$$

Finally, solving for $n$ and keeping only the positive solution gives

$$
n=\frac{-K_{2} W+\sqrt{\left(K_{2} W\right)^{2}-4 K_{1} W^{2}\left(C_{D_{o}}+\frac{2 T}{\rho V^{2} S}\right)}}{\frac{4 K_{1} W^{2}}{\rho V^{2} S}} .
$$

In the limiting condition the thrust term $T$ becomes the thrust available and is found for a range of velocities during wind tunnel testing. Using this thrust available data the load factor can be plotted with respect to velocity. This plot provides a visual representation of how the load factor is limited by the thrust available, see Fig. (3.5).

The definition of the load factor can be used to express its limitations in terms of the maximum coefficient of lift.

$$
n \equiv \frac{L}{D}=\frac{\rho V^{2} C_{L} S}{2 W}
$$

In the limiting condition $C_{L}$ becomes $\left(C_{L}\right)_{\max }$.

$$
n_{\max }=\frac{\rho V^{2}\left(C_{L}\right)_{\max } S}{2 W}
$$

A plot of load factor verses velocity for both the thrust available condition and the maximum lift coefficient condition is shown in Fig. (3.5). It should be noted that the load factor is also constrained by the structural limits of the aircraft. A discussion of this constraint will not be given here. This subject is addressed briefly by Anderson[12]. 


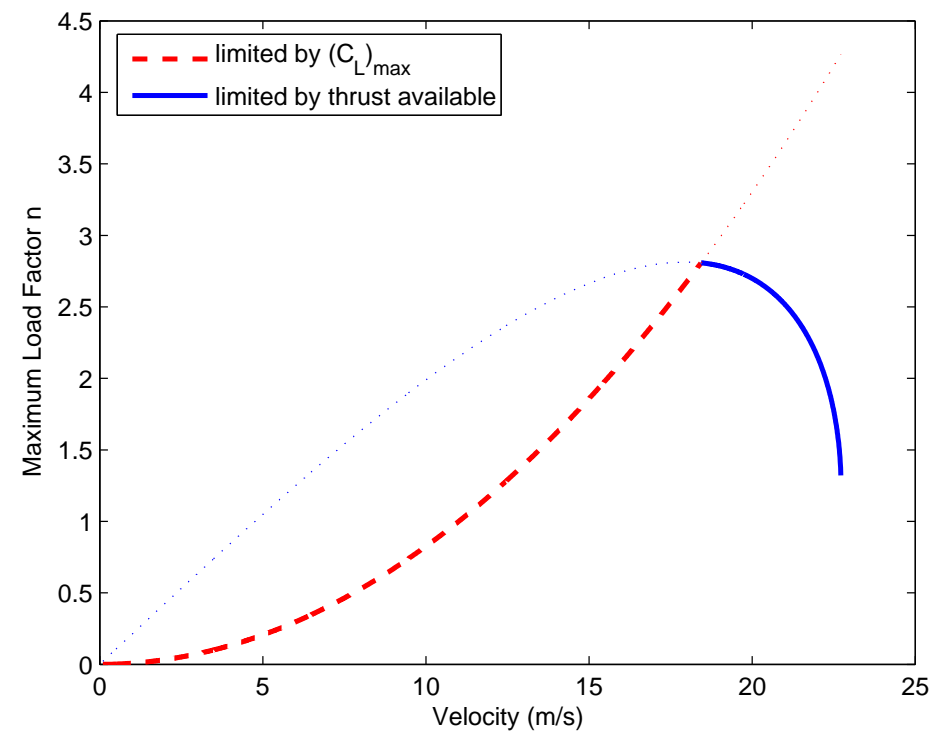

Figure 3.5: Maximum load factor verses velocity for the two limiting conditions.

Figure (3.5) provides the necessary information needed to calculate turn radius, turn rate, and bank angle for a given velocity. These parameters can be plotted with respect to velocity. Maximum and minimum values can be determined graphically. Example plots of minimum turn radius and maximum turn rate are shown below in Fig. (3.6). These plots were found by combining the results of Fig. (3.5) with Eq. (3.7) for turn radius and Eq. (3.8) for turn rate. Notice that both limiting conditions are represented. 

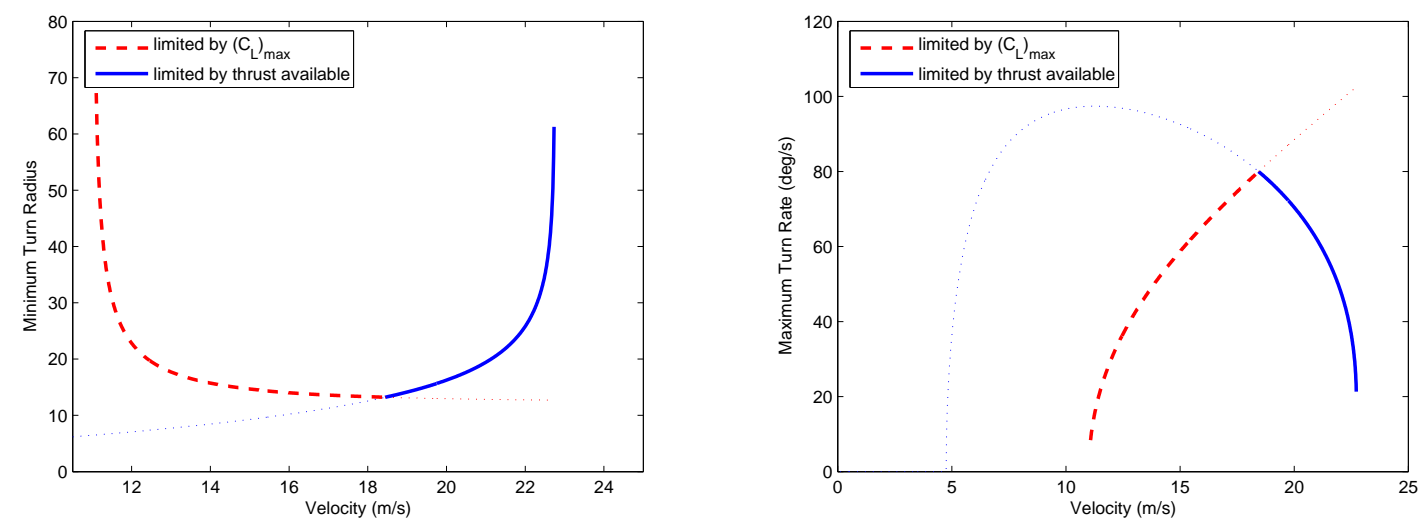

Figure 3.6: Minimum turn radius(left) and maximum turn rate(right).

For the minimum turn radius plot all possible turn radii are represented by the area above the bolded curves. At a given velocity the bolded curves represent the minimum turn radius for that velocity. The same principles apply to the maximum turn rate graph except the area of interest lies below the bolded curves. 


\section{Chapter 4}

\section{Results}

\subsection{Introduction}

This chapter discusses the actual flight testing of a small electric UAV. The first two sections give a brief description of the test aircraft, data acquisition system, and related hardware. The remaining sections present the results of ground testing, the drag polar, and the performance of the aircraft.

\subsection{Hardware}

The test aircraft chosen for this work was a commercially available flying wing called Unicorn. The Unicorn is made of expanded polypropylene (EPP) foam, supported with carbon spars and covered with Monokote. This plane was chosen for testing because it is inexpensive and durable. The Unicorn has successfully been used by Brigham Young University's MAGICC Lab to demonstrate coordinated maneuvers by multiple UAVs such as simultaneous arrival and perimeter tracking. The Unicorn that was flight tested is shown in Fig. (4.1). The wing span measured $1.06 \mathrm{~m}$. The wing area $(S)$ was $0.321 \mathrm{~m}^{2}$ and the complete airplane weight, including batteries, was $9.34 \mathrm{~N}$, (approximately $2 \mathrm{lb}$ ). 


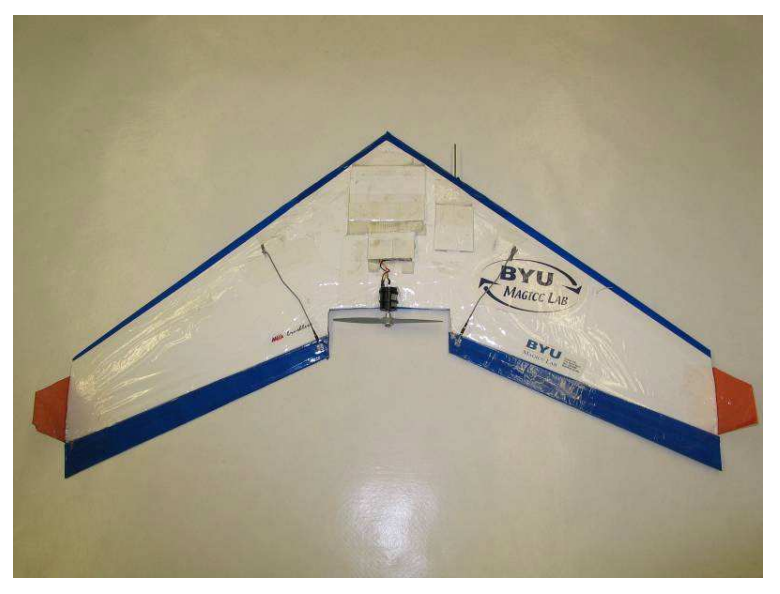

Figure 4.1: Unicorn small UAV used in flight tests.

The propulsion system for the test aircraft was a MEGA 16/15/6 brushless electric motor with a $7 \times 4$ inch propeller. Electric power was provided by two $11.1 \mathrm{~V}, 1500 \mathrm{mAh}$ lithium polymer batteries in parallel. The batteries used were manufactured by Kokam.

\subsection{Data Acquisition}

Data acquisition and control of the test aircraft was achieved using the Kestrel 2.0 autopilot and a ground station (shown in Fig. (4.2)). Standard autopilot sensors include a volt meter, differential pressure sensor, absolute pressure sensor, three rate gyros, and three accelerometers. Auxiliary sensors included a current shunt and a GPS antenna. Airspeed was previously measured on the autopilot by a total pressure tube connected to one side of a differential pressure sensor located on the autopilot. The pressure inside the aircraft was assumed to be the static pressure. Because the autopilot was located inside the fuselage it did not measure a true static pressure for the free stream air around the airplane. In order to obtain more accurate velocity measurements the total pressure tube was replaced by a pitotstatic tube. A Digikey G-P4V mini 5-inch differential pressure sensor was substituted for the differential pressure transducer on the autopilot. The pitot-static tube had a diameter of 1/8 inch and was purchased from Dwyer Instruments, Inc. Fig. (4.3) shows the pitotstatic tube and the Digikey differential pressure sensor. The pitot-static tube connected to the 
Digikey pressure sensor gave an accurate measurement of the difference between the total and static pressure. This made it possible to accurately measure aircraft velocity.
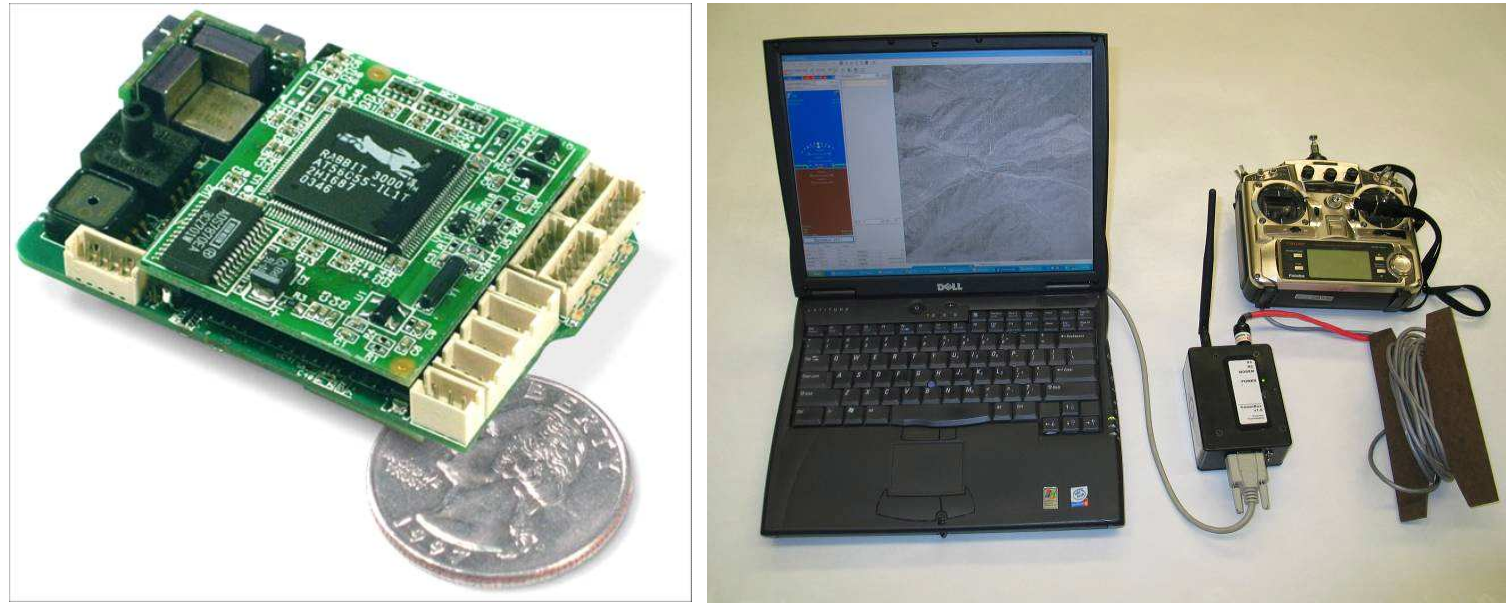

Figure 4.2: Kestral 2.0 autopilot, photo used with permission, Procerus Technologies(left). Ground station(right).
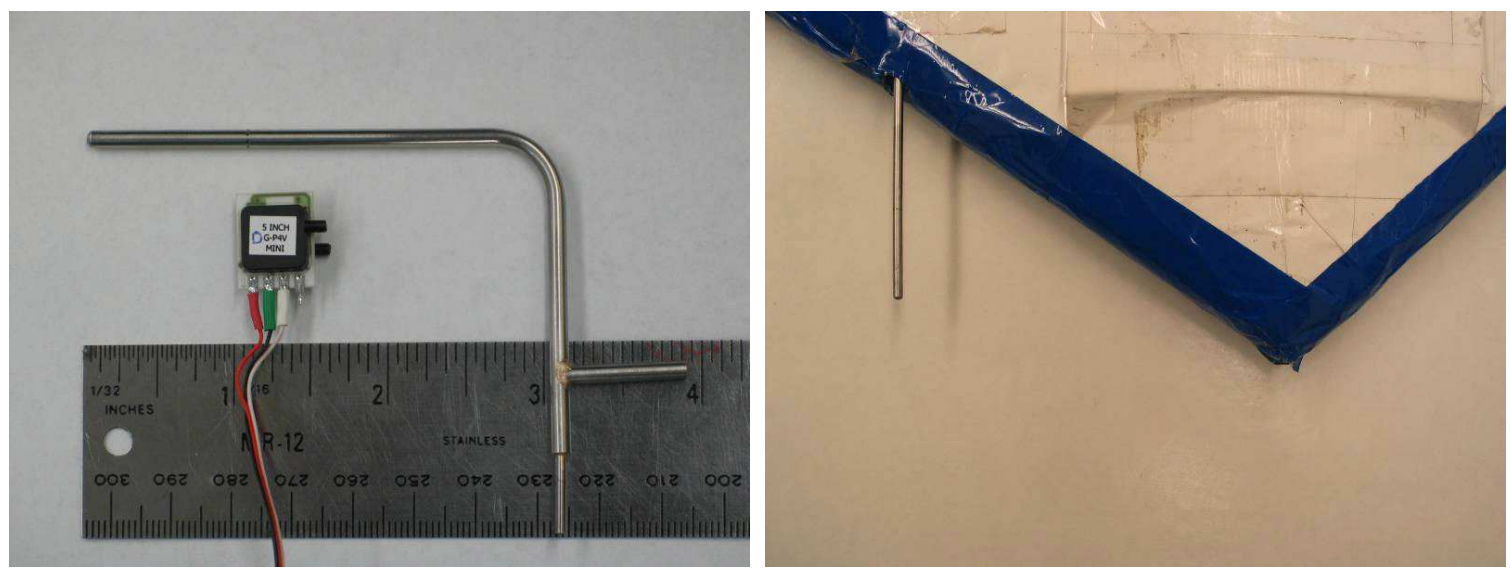

Figure 4.3: Dwyer 1/8 inch diameter pitotstatic tube and Digikey G-P4V mini 5 inch water differential pressure sensor(left). Pitotstatic tube shown installed on test aircraft at the leading edge near the nose (right). 
The ground station used for flight testing includes a communications box (commbox) that sends commands to and receives information from the airplane via a $900 \mathrm{MHz}$ shared frequency RF link. The commbox was connected to a laptop computer where a graphical user interface allowed a person on the ground to view measurements made on the airplane in real time. The user interface was also used to program desired flight settings, plan and upload GPS waypoint flight paths to the UAV, and log telemetry data transmitted from the test aircraft to the ground station.

\subsection{Propeller-Motor Efficiency}

The efficiency of the propeller-motor combination measured during wind tunnel testing is displayed in Fig. (4.4). Actual data points are shown, as well as the surface created by interpolating between the data points. Efficiency values range from 0.22 at high airspeeds and low power to 0.53 at mid-range airspeeds and high power.

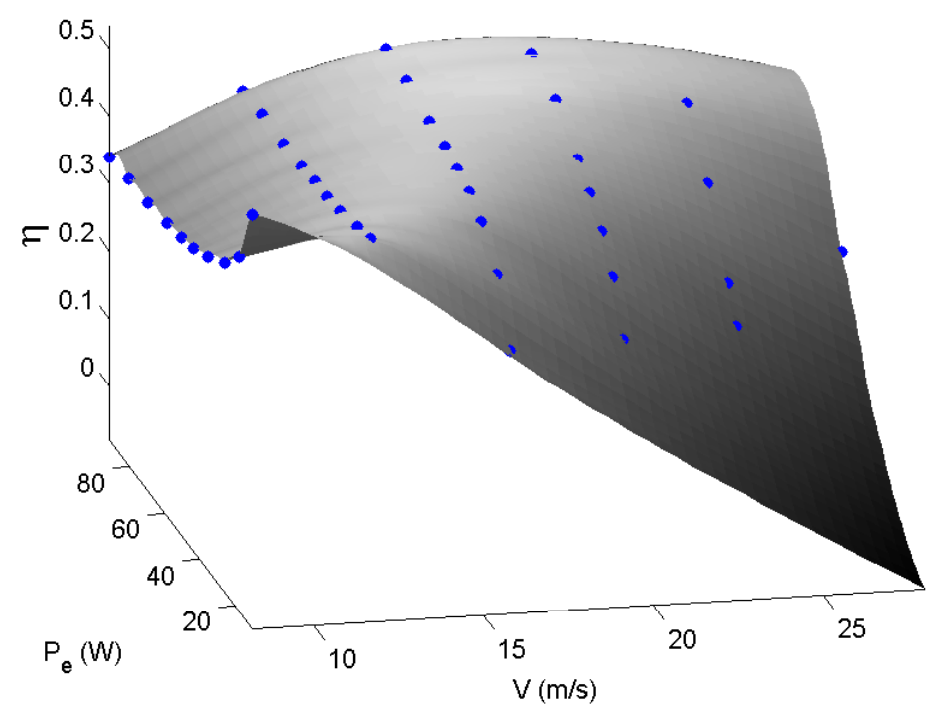

Figure 4.4: Propeller-motor efficiency surface of a MEGA

$16 / 15 / 6$ brushless motor and a $7 \times 4$ propeller. 
Figure. (4.5) shows data points for the average efficiency during each run of flight testing. Error for the run efficiencies ranged from approximately 0.023 to 0.052 .

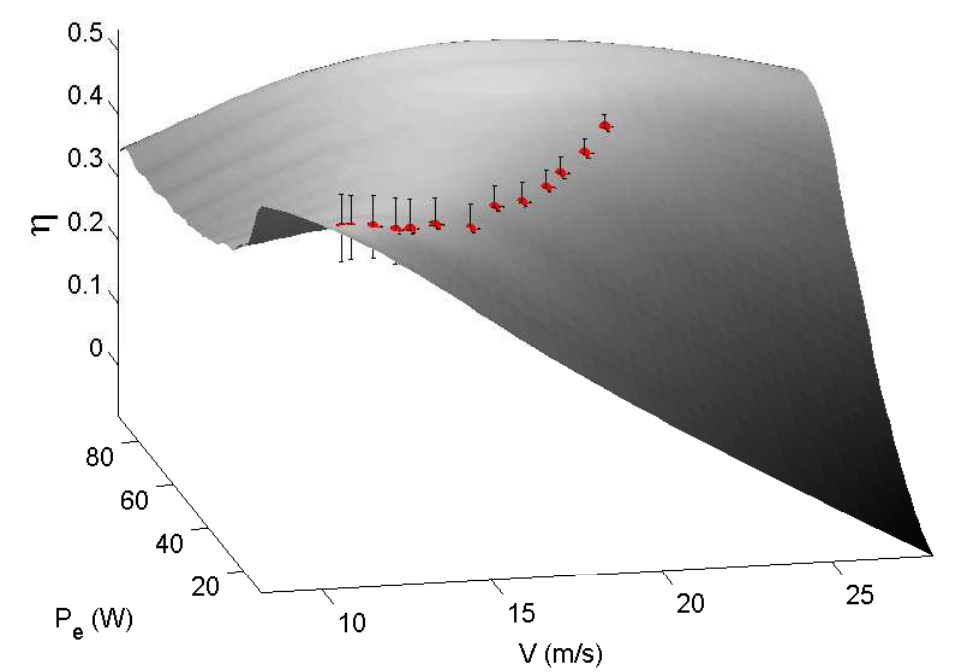

Figure 4.5: Efficiency surface showing average run efficiency.

\subsection{Drag Polar}

Figure (4.6) displays the measured drag polar data for the Unicorn UAV. Two forms of the drag polar equation can be estimated from this data. First, Eq. (4.1) and second, making the assumption that minimum drag occurs at zero lift, Eq. (4.2). 


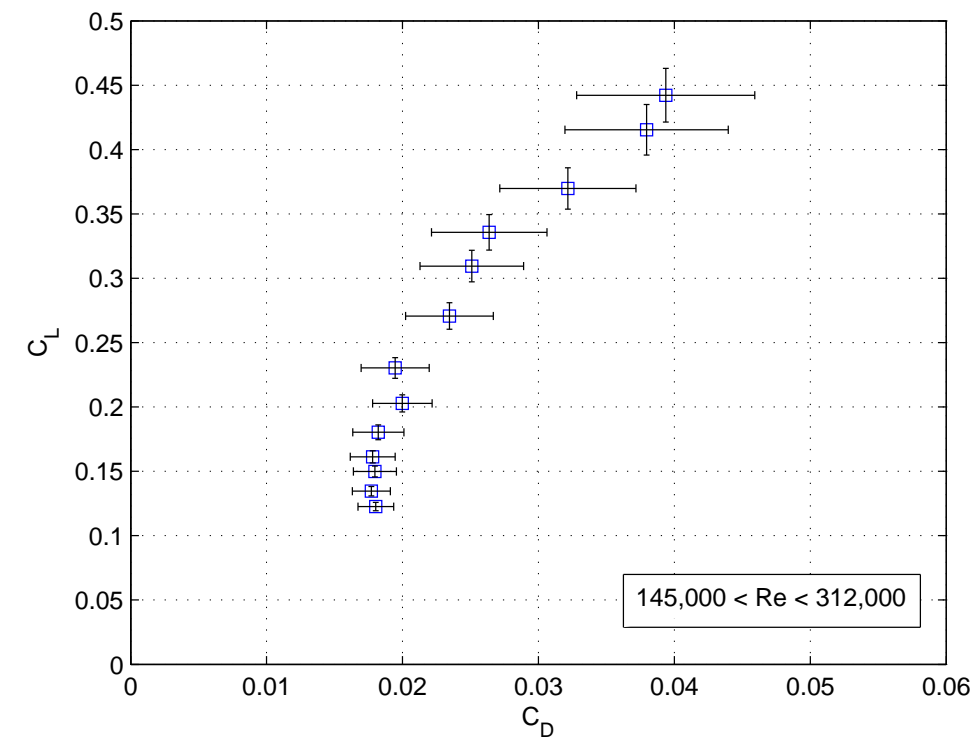

Figure 4.6: Drag polar of the Unicorn UAV. Error represents a 95\% confidence interval.

$$
\begin{gathered}
C_{D}=C_{D_{o}}+K_{2} C_{L}+K_{1} C_{L}^{2} \\
C_{D}=C_{D_{o}}+K C_{L}^{2} .
\end{gathered}
$$

To find the coefficients of Eq. (4.1) the flight test data was curve fit to a second order polynomial. Using this method $C_{D_{o}}$ was found to be $0.0213 \pm 0.0005, K_{1}$ was $0.22 \pm 0.02$, and $K_{2}$ was $-0.056 \pm 0.004$. The drag polar created from Eq. (4.1) and these coefficients is plotted with flight test data in Fig. (4.7). The $R^{2}$ value for this model is 0.99 . 


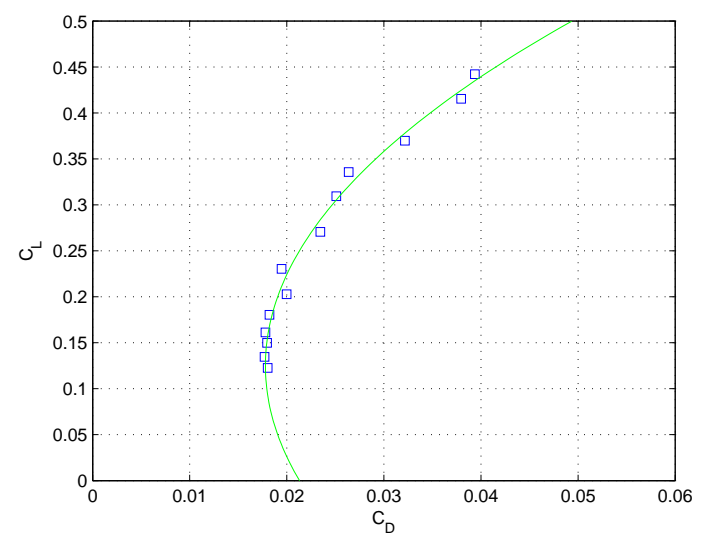

Figure 4.7: Drag polar superimposed on flight test results.

A plot of $C_{D}$ vs $C_{L}^{2}$ can be used to find $C_{D_{o}}$ and $K$ for the drag polar given in Eq. (4.2). If the data is fit with a straight line, then $C_{D_{o}}$ is equal to the y-intercept and $K$ is equal to the slope. The left side of Fig. (4.8) shows $C_{D}$ vs $C_{L}^{2}$ for the Unicorn UAV. $C_{D_{o}}$ was found to be $0.015 \pm 0.001$ and $K$ was found to be $0.13 \pm 0.03$. The right side of Fig. (4.8) shows the drag polar for the coefficients just mentioned plotted on top of flight test data. The $R^{2}$ value for this model was 0.97 .
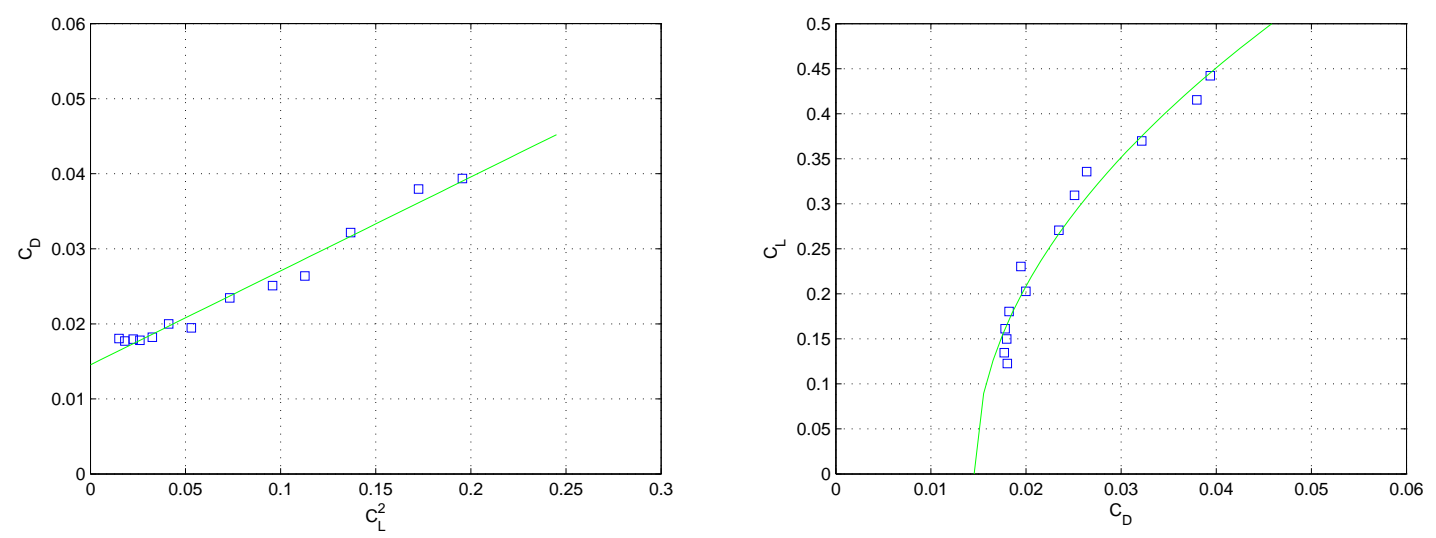

Figure 4.8: $C_{D}$ vs $C_{L}^{2}$ for the Unicorn UAV(left). Simplified drag polar superimposed on flight test results (right). 
The two forms of the drag polar presented here provide slightly different models. First, $C_{D}=0.02-0.06 C_{L}+0.22 C_{L}^{2}$, and Second, $C_{D}=0.015+0.13 C_{L}^{2}$. The first model fits the measured drag polar data better. The $R^{2}$ value for this model was 0.99 as opposed to 0.97 for the simplified model. Both of these models predict slightly different power required curves and maximum velocities. The second model predicts a maximum velocity of $23.1 \mathrm{~m} / \mathrm{s}$ and the first predicts $22.6 \mathrm{~m} / \mathrm{s}$. Maximum velocity found from flight testing was $22.1 \mathrm{~m} / \mathrm{s}$. The first model is closer to the measured value. There is some evidence that the first model is a better representation of the drag polar for the Unicorn UAV. Therefore this model of the drag polar will be used to find the remaining results presented in this thesis.

The plot of the drag polar shown in Fig. (4.6) has error bars that reach as much as $17 \%$ of the total value, even though the data is well behaved. The error in efficiency shown in Fig. (4.5) is between 5 and $12 \%$ of the total value. In both of these plots only a small fraction of the error is due to measurement variation. The majority of the error is a result of bias error. The bias error could also be referred to as instrument error. Table 4.1 displays the maximum bias errors that were observed during preliminary testing.

The error in the thrust measurement made during wind tunnel testing is not reported here because it was not significant. It would be valuable for future work to find sensors with reduced bias error that still meet the limited size and weight requirements of small UAVs.

Table 4.1: Bias error for measurements made during wind tunnel testing and flight testing. Values are given at the $95 \%$ confidence level.

\begin{tabular}{rrr} 
Sensor & Bias Error & Units \\
\hline voltage & \pm 0.20 & Volt \\
current & \pm 0.16 & Amp \\
airspeed & \pm 0.25 & $\mathrm{~m} / \mathrm{s}$
\end{tabular}




\subsection{Power Required and Maximum Velocity}

Power available and power required are both plotted in Fig. (4.9). For the Unicorn UAV maximum velocity occurred at $22.6 \pm 0.3 \mathrm{~m} / \mathrm{s}$. When maximum throttle was commanded during flight testing the measured airspeed averaged $22.1 \pm 0.25 \mathrm{~m} / \mathrm{s}$.

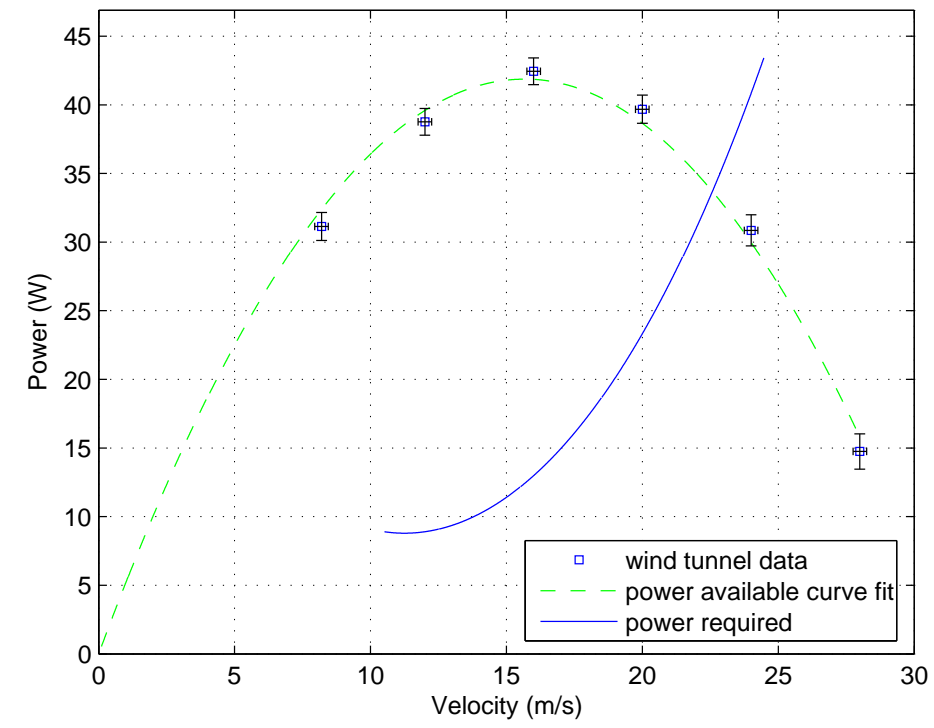

Figure 4.9: Power available and power required for the Unicorn UAV powered by a MEGA $16 / 15 / 6$ brushless motor with a $7 \times 4$ propeller.

\subsection{Minimum Velocity}

Minimum velocity was found by programming the autopilot to control a constant airspeed, altitude, and heading and then by reducing the desired airspeed until minimum velocity was reached. As the airspeed approached minimum velocity one of two behaviors was observed. Either the airplane would maintain pitch and heading but could no longer maintain desired altitude and would begin to descend, or the airplane would begin rolling violently to the right and left due to the autopilot's attempt to maintain altitude and heading despite the stall occurring on the wings. When either condition occurred the aircraft's current airspeed was recorded as the minimum velocity. For the Unicorn UAV, minimum 
velocity was found to be $10.5 \pm 0.25 \mathrm{~m} / \mathrm{s}$. This minimum velocity corisponds to a maximum lift coeficient of $0.44 \pm 0.02$.

\subsection{Rate of Climb}

A plot of rate of climb verses velocity for the Unicorn UAV is shown in Fig. (4.10). Maximum rate of climb was found to be $3.6 \mathrm{~m} / \mathrm{s}$ and is achieved at an airspeed of $13.4 \mathrm{~m} / \mathrm{s}$. Also shown in Fig. (4.10) is maximum climb angle verses velocity. For the Unicorn UAV the velocity for maximum climb angle $10.5 \mathrm{~m} / \mathrm{s}$ which is stall velocity. In order to avoid the danger of stalling a slightly lower airspeed and climb angle should be used for maximum climb angle.
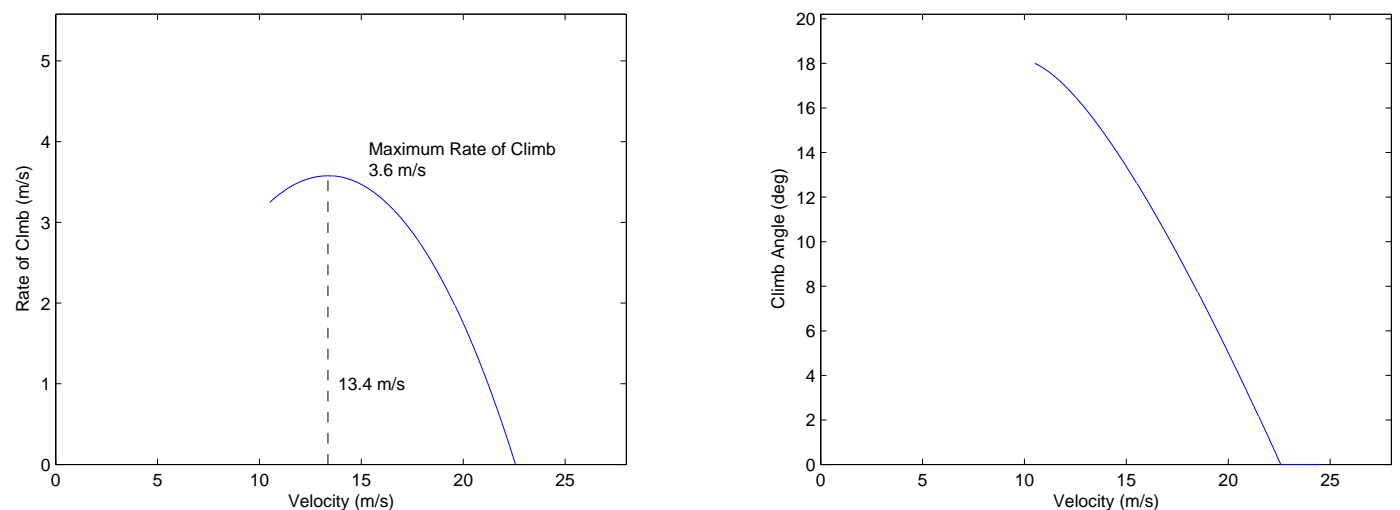

Figure 4.10: Rate of climb verses velocity(left). Maximum climb angle verses velocity(right).

\subsection{Range and Endurance}

Graphical results showing velocity for maximum range and endurance appear in Fig. (4.11). Velocity for maximum endurance is shown on the power required plot (left) and was found to be $11.3 \mathrm{~m} / \mathrm{s}$. Velocity for maximum range is shown on the thrust required plot (right) and was found to be $13.2 \mathrm{~m} / \mathrm{s}$. 

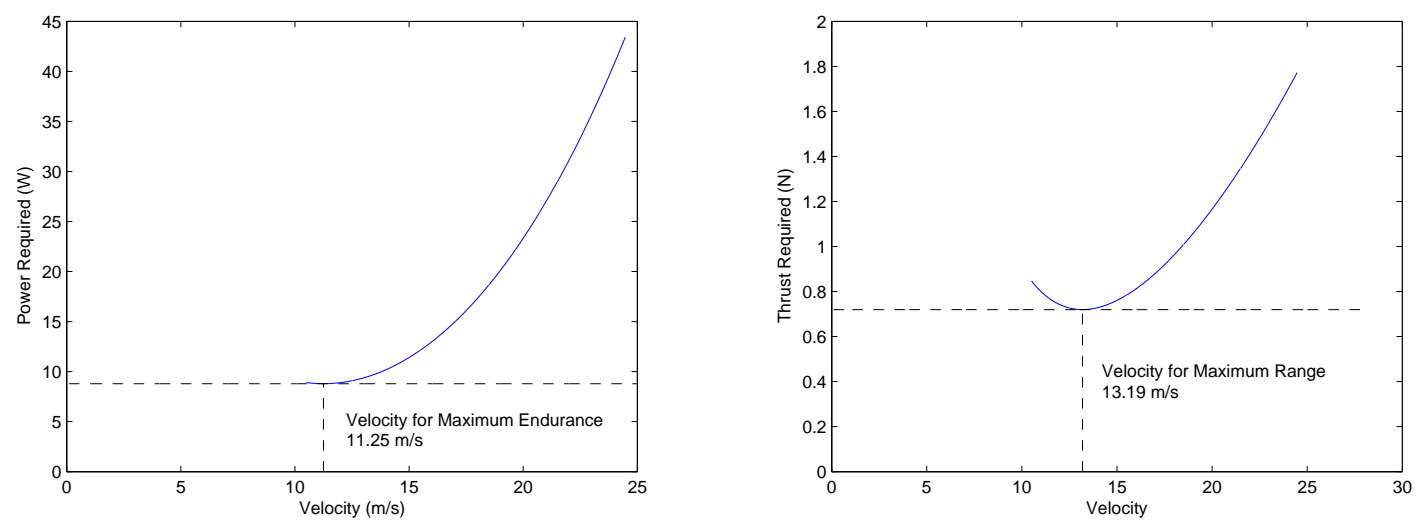

Figure 4.11: Velocity for maximum range and maximum endurance.

\subsection{Turn Performance}

Turn performance parameters found from the drag polar of the Unicorn UAV are shown below in Fig. (4.12). Minimum turn radius was 13.2 meters, maximum turn rate was 80 degrees/s, and maximum bank angle was 69.1 degrees. All of these values occur at $18.4 \mathrm{~m} / \mathrm{s}$. This means the best turn performance is achieved at $18.4 \mathrm{~m} / \mathrm{s}$. This also corresponds to the velocity for maximum load factor. 

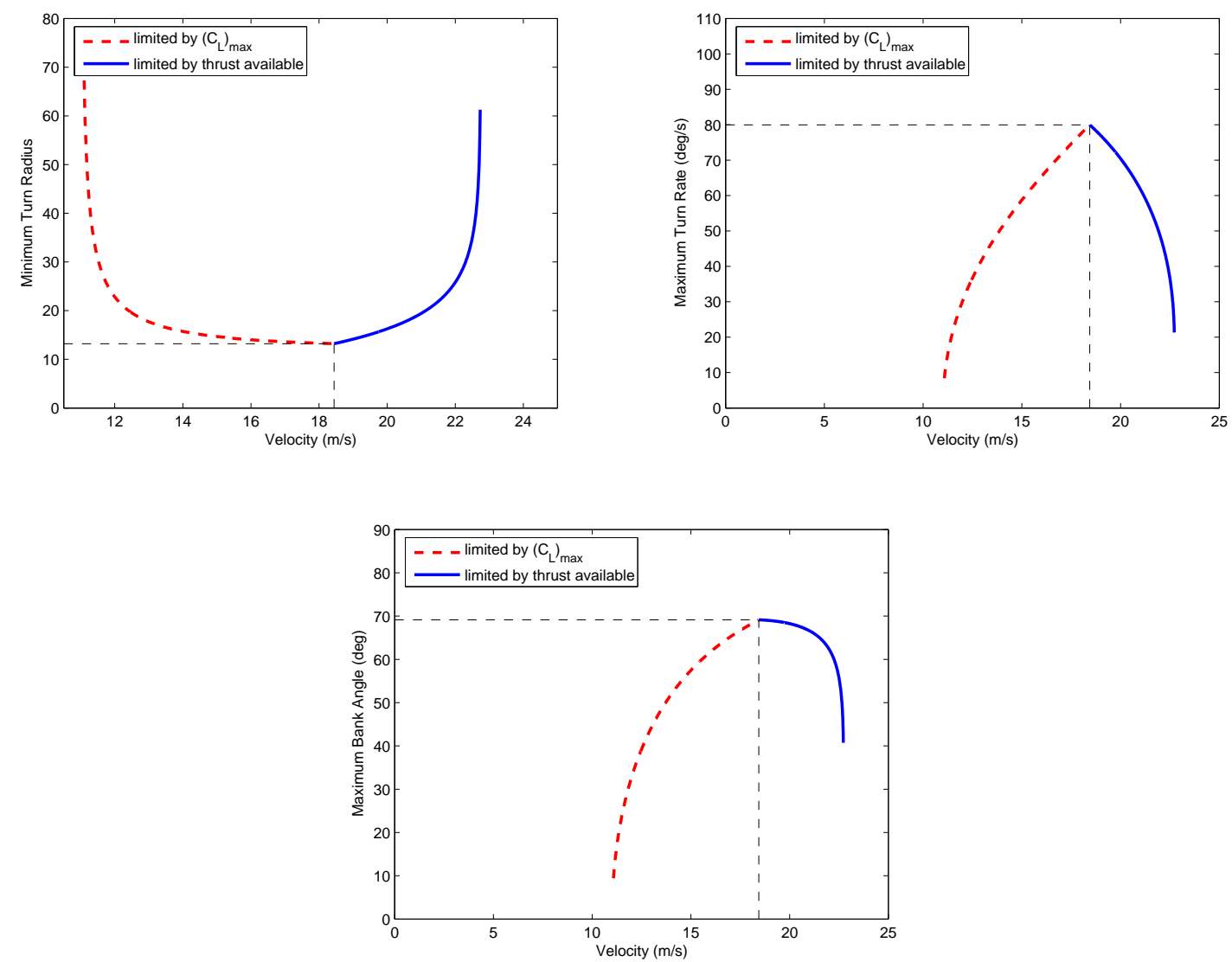

Figure 4.12: Turn performance parameters for the Unicorn UAV. 


\section{Chapter 5}

\section{Applications}

\subsection{Introduction}

The drag polar and performance parameters of a small UAV can be used to further develop the UAV and optimize its use. Using information found from flight testing, control algorithms can be improved, insights into the effect of changes to the airframe and payload can be gained, and performance information can provide the end user with optimal settings for a desired mission. This chapter gives some examples of how the drag polar and performance parameters can be used to advance the use of small electric UAVs.

\subsection{Throttle Control}

The block diagram of an airspeed controller is shown in Fig. (5.1). Prior to this research this was the feedback control used to regulate airspeed on the Kestral autopilot. If a model of the throttle-airspeed relationship can be obtained then feedforword may be used to improve this controller. Feedforward can decrease overshoot and decrease error between the desired airspeed and the actual airspeed. A block diagram that includes a feedforward model is shown in Fig. (5.2)

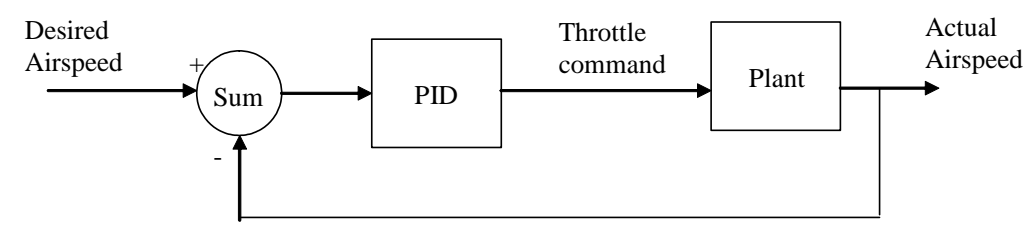

Figure 5.1: PID airspeed controller. 


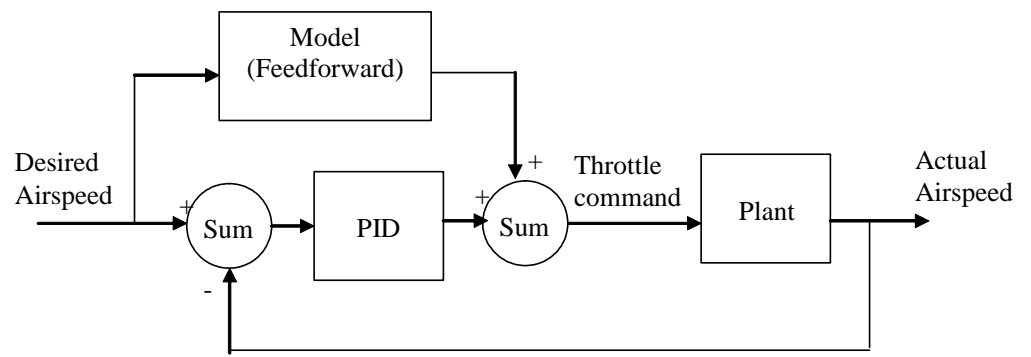

Figure 5.2: PID airspeed controller with feedforward.

After preliminary attempts to determine the drag polar for the the Unicorn UAV yielded data that was unacceptably noisy, a feedforward model was implemented. This model was simply the slope of a line between zero throttle and zero airspeed and maximum throttle and maximum airspeed(observed from initial testing). The results of this improvement are shown in Fig. (5.3). If desired, a more accurate model can be found for various flight conditions by combining wind tunnel data and power required terms found from flight testing.
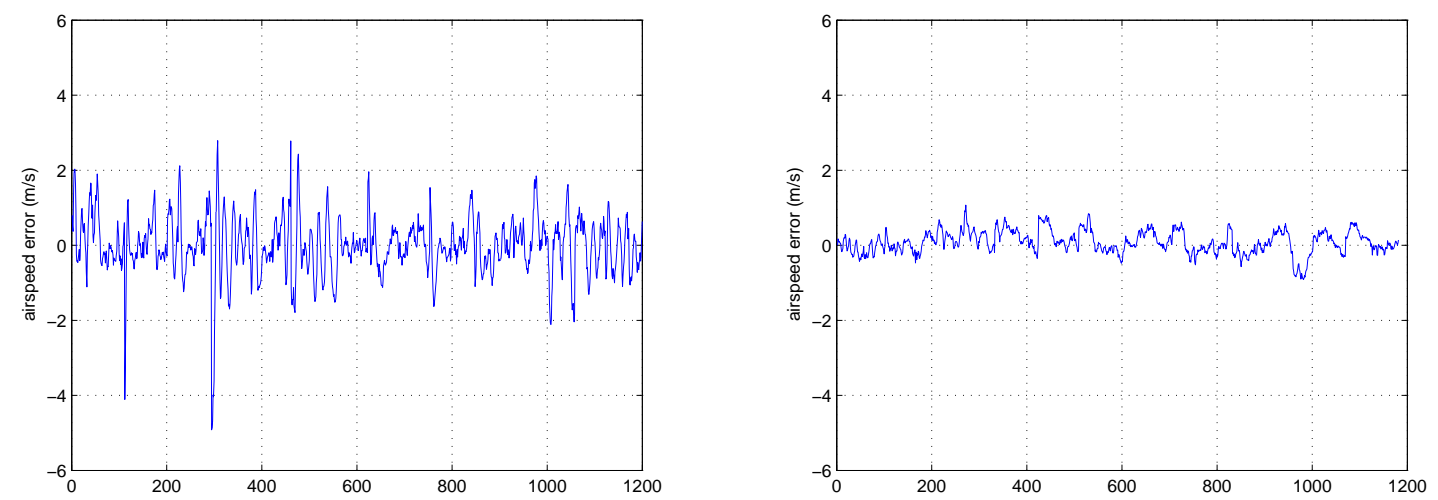

Figure 5.3: Airspeed error before feedforward(left) and after feedforward(right). 


\subsection{Climb Control}

A typical method for climbing a UAV from one altitude to another is to command maximum throttle, control airspeed from pitch, and set a desired airspeed. Without a knowledge of the aircraft's performance this desired airspeed must be chosen arbitrarily. However, climb performance data can define what the desired airspeed should be for two conditions, steepest climb and fastest climb. For steepest climb desired airspeed should be set to airspeed for maximum climb angle. For the fastest climb, desired airspeed should be set to airspeed for maximum rate of climb.

\subsection{Mission Planning}

Range and endurance can be very important parameters in mission planning. If the UAV needs to fly a great distance the desired airspeed should be set to the velocity for maximum range. If the UAV needs to remain in the air a long time, then the desired airspeed should be set to the velocity for maximum endurance.

If it is assumed that the batteries of an electric UAV discharge at at constant rate and voltage remains constant then the following equations may be used to estimate the endurance and range of the aircraft.

$$
\begin{aligned}
& \text { endurance }=\frac{C}{i E}=\frac{C \eta}{C_{D_{o}} \frac{1}{2} \rho V^{3} S+K_{2} W V+\frac{K_{1} W^{2}}{\frac{1}{2} \rho V S}} \\
& \text { range }=\frac{C}{(i E) / V}=\frac{C \eta}{C_{D_{o}} \frac{1}{2} \rho V^{2} S+K_{2} W+\frac{K_{1} W^{2}}{\frac{1}{2} \rho V^{2} S}}
\end{aligned}
$$

Where $C$ is the energy capacity of the batteries in units of joules, $i$ is the battery current, $E$ is the battery voltage, and $\eta$ is the motor propeller efficiency. If the current draw and flight time are recorded during a mission then a report could be continuously updated as to how munch flight time and distance remain in the mission. 


\subsection{Unpowered Flight}

Unpowered, or gliding, flight is another area where knowledge of aircraft performance can be applied. In the event that power fails while the UAV is in flight it would be important to know what conditions will provide maximum range and maximum flying time. Flying at minimum glide angle, measured from horizontal, will enable maximum range. In order to achieve minimum glide angle the airplane should be flown at the velocity for minimum thrust required. In order to maintain the maximum time aloft without power, the aircraft should be flown to minimize sink rate. This is achieved at the velocity for minimum power required [12].

\subsection{Model Validation}

Flight test results can also be used to validate engineering models. A method of predicting the drag polar of small unmanned aircraft is given by Bowman and Snyder [13]. Predictions made by this method for the Unicorn UAV are presented in Fig. (5.4). Velocities for the Unicorn UAV range from stall at $10.5 \mathrm{~m} / \mathrm{s}$ to maximum velocity at $22.1 \mathrm{~m} / \mathrm{s}$ This range corresponds to Reynolds numbers from 145,000 to 312,000. Predicted drag polars for both the low and high Reynolds numbers assuming laminar and turbulent flow are shown in Fig. (5.4). For the Unicorn UAV it appears that the laminar flow model is more accurate at low Reynolds numbers and that the turbulent model is more accurate at high Reynolds numbers. 

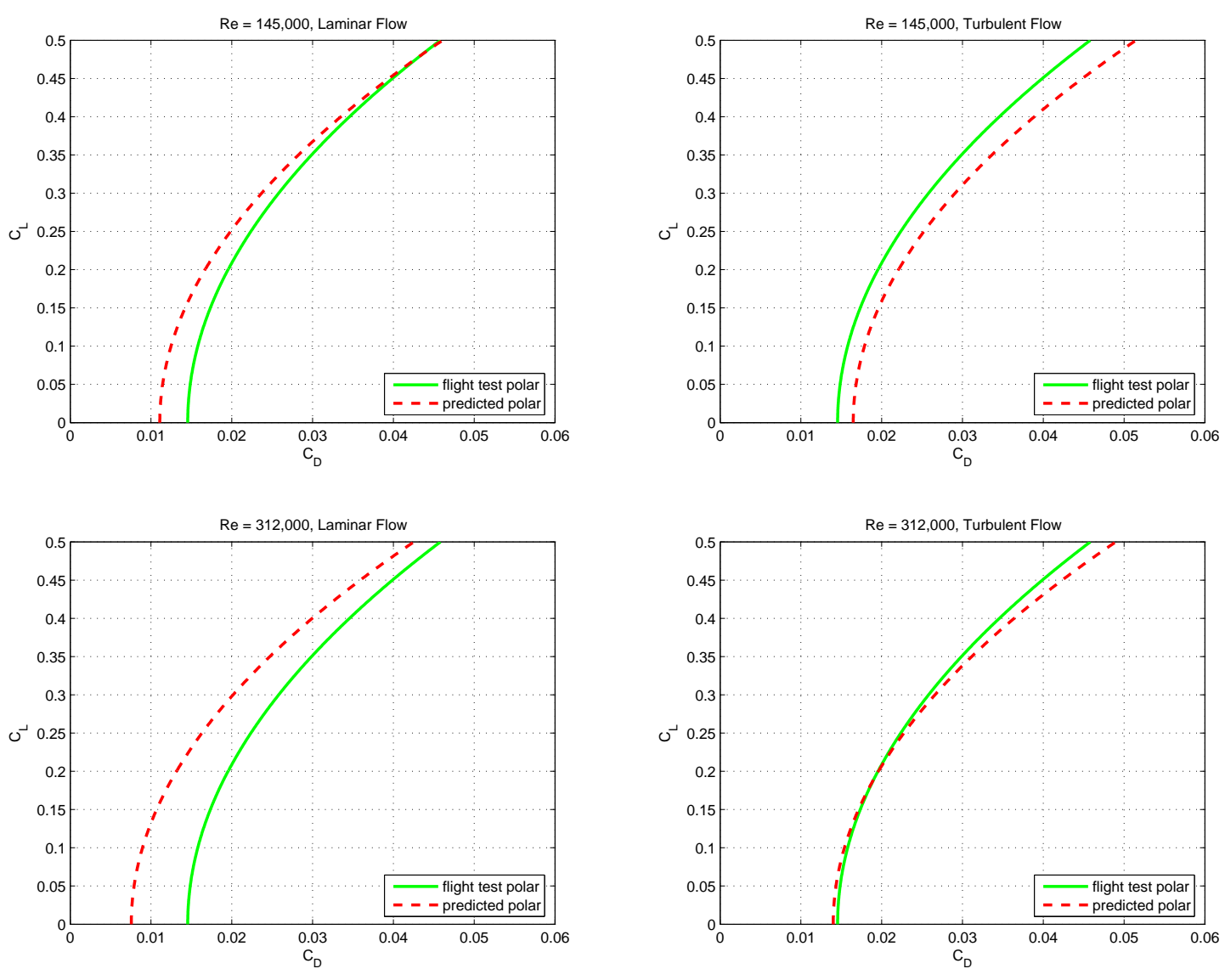

Figure 5.4: Predicted drag polars verses flight test results. 


\section{Chapter 6}

\section{Conclusions and Recommendations}

\subsection{Conclusions}

Flight test methods have been developed for small electric powered UAVs. These methods have been used successfully to find the drag polar and many performance parameters including range, endurance, climb performance, and turn performance for a small UAV called Unicorn. Methods consist of measuring aircraft dimensions and properties, wind tunnel testing to characterize the efficiency of the motor-propeller combination, and flight testing to determine the coefficient of lift and the coefficient of drag for the airplane over a range of velocities.

The drag polar data found from flight testing was well behaved. However, on a $95 \%$ confidence interval the error was as much as $17 \%$ of the total value. This error was due to the bias error in the current and voltage measurement. Using drag polar data $C_{D}=$ $0.02-0.06 C_{L}+0.22 C_{L}^{2}$ was determined to be the drag polar for the Unicorn UAV.

The Kestral 2.0 autopilot was used as the flight control and data acquisition system during flight testing. Some changes to sensors and control loops were needed to improve the accuracy of velocity measurements. The advantages of using the Kestral autopilot for flight testing small UAVs are that it is small, only weighs $20 \mathrm{gm}$, it easily integrates new sensors, the source code is available and can be changed as needed, and measured values are accessible through standard telemetry.

The drag polar and performance parameters found from the test methods detailed in this thesis are a valuable tool in the development use of small electric UAVs. Control algorithms can be improved and performance information can provide the end user with optimal 
settings for a desired mission. Flight test results are also useful in validating engineering models.

\subsection{Future Work}

Some aspects of flight testing small electric UAVs can still be improved. Future work should include more precise sensors that meet the limitations of small electric UAVs. This will help to reduce the error in the drag polar and subsequent calculations. Also, future work should develop and test the alternative methods for finding the drag polar that are outlined in Sec. (2.5).

More applications of the performance data need to be discovered. The throttle feed forward model in Sec. (5.2) remains to be found and implemented for a small UAV. Much work could also be done in the area of mission planning. Performance parameters could be used in conjunction with software and optimization tools to make it easier for end users to plan missions that are efficient and push the limits of small UAVs. 


\section{Bibliography}

[1] Kimberlin, R., Flight Testing of Fixed-Wing Aircraft, American Institue of Aeronautics and Astronautics, 2003.

[2] Foster, T. and Bowman, J., "Dynamic Stability and Handling Qualities of Small Unmanned- Aerial Vehicles," 43rd AIAA Aerospace Sciences Meeting and Exhibit, Reno, Nevada, January 2005, AIAA-2006-1023.

[3] Higashino, S. and Ly, U., "Development of a UAV Flight-Test Vehicle at the University of Washington," 2nd AIAA "Unmanned Unlimited" Systems, Technologies, and Operations, Workshop and Exhibit, September 2003, AIAA 2003-6583.

[4] Brinker, J. and Wise, K., "Flight Testing of Reconfigurable Control Law on the X-36 Tailless Aircraft," AIAA Journal of Guidance, Control and Dynamics, Vol. 24, No. 5, Sep.-Oct. 2001, pp. 903-909.

[5] Murray, J. E., Pahle, J. W., Thornton, S. V., S. Vogus, T. F., Mello, J. D., and Norton, B., "Ground and flight evaluation of a small-scale inflatable-winged aircraft," 40th AIAA Aerospace Sciences Meeting and Exhibit, Reno, Nevada, January 2002, AIAA2002-0820.

[6] Seanor, A., Flight Testing of a Remotely Piloted Vehicle for Aircraft Parameter Estimation Purposes, Ph.D. thesis, West Virginia University, Virginia, 2002.

[7] Budd, G., "Operation and Research Aspects of Radio Controlled Flight Test Program,” Tech. rep., 1993, NASA Technical Memorandum, 104266.

[8] Williams, W. and Harris, M., "The Challenges of Flight-Testing Unmanned Air Vehicles," Systems Engineering, Test and Evaluation Conference, Sydney, Australia, October 2002. 
[9] Hiller, B., "Estimation of Drag Characteristics of a Fixed Wing Unmanned Aerial Vehicle," AIAA's 1st Technical Conference and Workshop on Unmanned Aerospace Vehicles, Portsmouth, Virginia, May 2002, AIAA-2002-3495.

[10] Abdulrahim, M., "Flight Performance Characteristics of a Biologically-Inspired Morphing Aircraft," 43rd AIAA Aerospace Sciences Meeting and Exhibit, Reno, Nevada, January 2005, AIAA-2005-345.

[11] Phillips, W. F., Mechanics of Flight, John Wiley and Sons, Inc, 2004.

[12] Anderson, J. D., Aircraft Performance and Design, McGraw-Hill, 1999.

[13] Bowman, W. J. and Snyder, D., “A Less Minimalist Approach to Teaching Aircraft Design," 44th AIAA Aerospace Sciences Meeting and Exhibit, Reno, Nevada, January 2006, AIAA-2006-0094. 